\title{
A superação do capitalismo em questão: com que prática, em qual direção?
}

A superação do capitalismo em questão: com que prática, em qual direção?

La superación del capitalismo en cuestión: ¿con qué prácticas, en qué dirección?

Le dépassement du capitalisme en question : avec quelles pratiques, et dans quelle direction?

Overcoming capitalism in question: with which practices, in which direction?

\section{Eveline Algebaile e Floriano José Godinho de Oliveira}

\section{(2) OpenEdition}

\section{Journals}

\section{Edição electrónica}

URL: http://journals.openedition.org/espacoeconomia/11131

DOI: 10.4000/espacoeconomia. 11131

ISSN: 2317-7837

\section{Editora}

Núcleo de Pesquisa Espaço \& Economia

\section{Refêrencia eletrónica}

Eveline Algebaile e Floriano José Godinho de Oliveira, « A superação do capitalismo em questão: com que prática, em qual direção? », Espaço e Economia [Online], 17 | 2020, posto online no dia 07 abril 2020, consultado o 21 abril 2020. URL : http://journals.openedition.org/espacoeconomia/11131 DOI : https://doi.org/10.4000/espacoeconomia.11131

Este documento foi criado de forma automática no dia 21 abril 2020.

(c) NUPEE 


\title{
A superação do capitalismo em questão: com que prática, em qual direção?
}

\author{
A superação do capitalismo em questão: com que prática, em qual direção? \\ La superación del capitalismo en cuestión: ¿con qué prácticas, en qué dirección? \\ Le dépassement du capitalisme en question : avec quelles pratiques, et dans \\ quelle direction?
}

Overcoming capitalism in question: with which practices, in which direction?

Eveline Algebaile e Floriano José Godinho de Oliveira

\section{Uma introdução ao texto republicado: o que a pandemia revela sobre a cegueira capitalista?}

1 A gravidade da eclosão da pandemia do Covid-19 e a necessidade de debater os inúmeros problemas que a partir de então vêm se revelando nos reportaram ao debate promovido no XV Colóquio de Geocrítica, realizado na Universidade de Barcelona, em 2018, com o tema "Las ciencias sociales y la edificación de una sociedad postcapitalista", desafiadoramente proposto pelo Professor Horácio Capel. Recordamo-nos, em particular, do nosso estranhamento inicial do tema, por parecer dirigir nossa atenção para cenários futuros muito difíceis de traçar com ferramentas das ciências sociais que não nos expusessem ao risco das discussões especulativas. Mas também nos recordamos do momento seguinte, quando, buscando meios de pensar sobre o futuro com seriedade e rigor, percebemo-nos interpelando o passado e o presente com indagações novas, que nos proporcionavam interessantes deslocamentos no seu conhecimento e compreensão.

O texto aqui republicado resultou dessa provocação que, em nosso caso, levou-nos ao exercício de leitura e sistematização de formulações que nos ajudassem a compreender as condições de produção do futuro aninhadas nas relações que produzem a realidade 
capitalista presente. Nele, buscamos apresentar formulações de David Harvey e de Dardot e Laval a respeito das mudanças recentes do capitalismo, das realidades objetiva e subjetiva produzidas por essas mudanças, das tentativas reais de confrontação de sua lógica e das lições que podemos extrair dessas experiências para pensar sua superação. o que nos motivou a republicá-lo foi perceber o quanto as formulações desses autores, especialmente as realizadas na última década, apresentam coerentemente os caminhos que, no fim das contas, levaram nossas sociedades, não por desconhecimento, mas por descaso, à situação trágica agora vivida com a eclosão da pandemia.

São formulações que nos permitem perceber o quanto os sucessivos episódios de crise econômica ocorridos desde a década de 1970 vêm expondo aspectos dos limites estruturais do capitalismo que, por suas potencialidades destrutivas, deveriam merecer atenção mais rigorosa nos processos de decisão política dos governos nacionais e das organizações internacionais que funcionam como poderes supranacionais de fato. Trata-se, afinal, de limites relacionados de diferentes modos a graves riscos de desastres sociais, ambientais e econômicos que podem desmontar e inviabilizar, de forma extremamente rápida, as mais elementares condições de provisão e de sobrevivência que sustentam a vida coletiva no atual contexto.

Os sinais agudos desses riscos vêm sendo identificados e analisados por diversos ramos das ciências naturais, sociais e humanas. São nossos conhecidos, dando base a debates acadêmicos, políticos e midiáticos de boa repercussão, e motivando várias obras literárias e cinematográficas que apontam futuros distópicos nos quais a destruição das condições ambientais, a alteração brutal das condições climáticas, a deflagração de guerras genocidas, a supremacia das máquinas ou a disseminação de epidemias são destacadas ou combinadas de diferentes modos, ilustrando os lugares de desespero para os quais provavelmente vimos caminhando sem reações proporcionais à gravidade das ameaças.

5 A pandemia de Covid-19 é, sem dúvida, o evento contemporâneo que mais se aproxima dos cenários distópicos até então traçados. Não tanto pela gravidade da doença causada pelo vírus - que não é superior à de outros vírus responsáveis por tragédias recentes bem conhecidas, como a provocada pelo Ebola na África - , mas especialmente pela temporalidade e pela escala em que ela se dá, globalizando rapidamente uma experiência trágica que atravessa barreiras até então bem eficientes, como as relacionadas às hierarquias econômicas entre nações, entre continentes e entre classes sociais.

6 Ela produz uma tragédia moderníssima: seu modo decisivamente globalizado de realização, implicando uma ocorrência mundial praticamente simultânea, amplifica e socializa de forma imprevista os limites de seu enfrentamento, produzindo um quadro profundamente desconcertante, seja pela forma e rapidez com que produz a tragédia humana em larga escala, seja pela forma como revela os variados aspectos do despreparo mundial (não só dos países pobres!) para seu enfrentamento, seja, ainda, pela forma como evidencia o quanto são poderosas as formas mais egoístas, mesquinhas e destrutivas de interpretar os fatos e conduzir as escolhas e decisões.

7 Dos cenários distópicos construídos pela literatura, parece-nos que o delineado por Saramago em "Ensaio sobre a cegueira" (1995) talvez seja o que melhor ilustra os acontecimentos que agora vivemos em ato. Não apenas porque a situação narrada no livro se vincula, tal como agora, a uma epidemia cujo alcance e consequências são irrefreáveis, mas porque seu desenrolar nos faz conhecer mais claramente as 
angustiantes limitações políticas e sociais para enfrentá-la. No livro, uma misteriosa epidemia de cegueira biológica, produzida por um vírus desconhecido, revela formas de cegueira social que amplificam seus efeitos, assim como, na vida real, os efeitos trágicos da pandemia de Covid-19 resultam não somente da voracidade do novo vírus e da sua forma criativa de se movimentar, mas também, e talvez principalmente, da incapacidade da nossa sociedade de atribuir a adequada importância ao conhecimento que já se tinha dos riscos de eventos similares e das ações e meios que poderiam ter produzido melhores condições de enfrentá-los.

8 E como não se trata, certamente, de uma incapacidade generalizada, mas da hegemonia cruel das formas mais graves de cegueira social, é extremamente importante, neste momento, darmos visibilidade e destaque àqueles conhecimentos dos variados campos da ciência que avançaram na identificação dos acontecimentos naturais, econômicos e político-sociais que nos expunham aos riscos de sofrermos acontecimentos destrutivos e de não conseguirmos vê-los a tempo ou com a nitidez necessária para preparar seu enfrentamento.

9 No caso das ciências políticas e sociais, formulações como as de David Harvey (2014 e 2016) e de Dardod e Laval (2016 e 2017), a respeito das mudanças mais recentes do capitalismo, vinham, há mais de duas décadas, mostrando como as tentativas de solucionar as crises econômicas a favor do capital estavam produzindo aceleradamente o agravamento da erosão de condições ambientais, sociais e políticas claramente implicadas, agora, com a eclosão da pandemia e com os limites de sua contenção.

10 Analisando as perguntas e as respostas hegemônicas a respeito do caráter das crises dos anos1970 e de 2008, os autores mostram por vários caminhos que, sob o argumento farsesco de reorganizar a economia em bases sustentáveis, o capital vem impondo medidas de efeitos devastadores irrefreáveis sobre a vida humana, a sociabilidade e as condições planetárias, ilustrados de forma contundente, no cenário pandêmico, pela inocuidade de sistemas de saúde que, mesmo dispondo de modernos equipamentos, não conseguem usá-los devidamente porque perdem feio para a escala de alcance do vírus.

11 Há muito conhecimento útil para organizarmos a vida coletiva de forma não espoliativa, garantido condições que além de promoverem formas dignas de vida, proporcionem pontos de partida mais favoráveis para enfrentarmos as crises e os desastres, quando necessário. Mas esse conhecimento e as escolhas às quais ele pode nos levar foram e continuam sendo descartados em nome de uma acumulação voraz cujos efeitos se tornam incontornáveis. $O$ texto a seguir busca reconhecer e destacar parte do esforço de pensamento que pode nos ajudar a disputar outros futuros possíveis.

\section{A SUPERAÇÃO DO CAPITALISMO EM QUESTÃO: COM QUE PRÁTICAS, EM QUAL DIREÇÃO?}

12 Desde a crise estrutural instaurada nos anos 1970 e a consequente expansão das estratégias neoliberais, o debate sobre o fim do capitalismo e sobre os projetos de sociedade implicados com sua superação vêm apresentando variadas linhas de problematização dos limites estruturais do próprio capitalismo ${ }^{1}$ e dos modelos políticos implicados com a perpetuação ou a confrontação dos interesses do capital $^{2}$. Neste último caso, adquiriram claro destaque as discussões sobre a constituição de novas 
bases e formas de participação democrática nas decisões políticas relativas aos mais variados aspectos da vida coletiva.

A crise econômico-política deflagrada em 2008 parece ter colocado em novo quadrante essa discussão. Desde então, as resistências às estratégias neoliberais observadas especialmente em fins da década de 1990 e nos anos iniciais do século XXI passam a ser violentamente confrontadas por formas incisivas de restauração ou instauração de medidas econômicas ultraconservadoras e de práticas políticas vinculadas às orientações de ultradireita. Trata-se de medidas e práticas cujos efeitos sobre a estrutura e o funcionamento do Estado e da produção econômica, bem como sobre os direitos sociais e, em particular, os direitos relacionados ao trabalho, dentre outros aspectos, têm implicações evidentemente problemáticas em relação às próprias condições de organização de resistências e lutas contra a ordem hegemônica.

14 A intensificação da investida neoliberal e das instabilidades e conflitos dela decorrentes, a partir desse momento, torna ainda mais necessárias as indagações sobre as possibilidades, o conteúdo, as formas e a extensão das lutas anticapitalistas capazes de incidir de modo mais decisivo sobre o fim do capitalismo e de, ao mesmo tempo, constituir as bases objetivas e subjetivas da sua superação por relações econômicas, políticas e sociais de novo tipo.

As formulações de David Harvey ${ }^{3}$ e de Pierre Dardot e Christian Laval ${ }^{4}$ com respeito a essas questões são bastante expressivas dessa discussão em curso.

Em ambas, a questão da edificação de sociedades pós-capitalistas é enfrentada, mas as indagações e projeções sobre o futuro aparecem fortemente implicadas com a proposição de direções e estratégias que definam, desde o presente, variadas possibilidades organizativas que possam incidir sobre as próprias condições gerais de participação sócio-política, ampliando-as e modificando-as.

17 Ainda que de modos distintos, as duas formulações também dão significativo destaque à ideia de que a multiplicação e a intensificação de formas participativas não centralizadas, no presente, são fundamentais para a instauração de relações e de processos de formação subjetiva entendidos como primordiais para se fomentar qualquer modelo alternativo futuro.

18 A superação do capitalismo é explicitamente relacionada ao surgimento de novas relações de produção não centradas na propriedade, mas os componentes subjetivos dessas relações e suas condições concretas de realização social são especialmente destacados. Novas relações de produção só podem ser instauradas em vínculo profundo com a elaboração de formas de sociabilidade e de práticas políticas decisivamente distintas dos modelos de sociabilidade e governabilidade vinculados à democracia liberal.

19 Assim, as duas formulações, ao discutirem as possibilidades de superação do capitalismo, o fazem ressaltando que as lutas anticapitalistas não podem se limitar às formas de objeção permanente ao regime estabelecido e tão pouco à defesa das formas tradicionais de democracia, associadas à garantia de liberdades públicas. Nesse sentido, explicitam preocupações que em parte podem ser sintetizadas com a seguinte indagação de Harvey: “... o que nós, que acreditamos que o capital está na direção errada, consideramos ser a direção certa, e como devemos avaliar nosso progresso rumo à realização de nossos objetivos?"5. 
20 Ainda que a proposição de modelos alternativos de organização social seja tratada distintamente nas duas formulações, ambas dão especial atenção ao conteúdo e à forma de princípios, práticas e relações anticapitalistas que precisam ser explicitados para que as lutas pela superação do capitalismo não se limitem às objeções e defesas acima referidas.

21 A esse respeito, Dardot e Laval ressaltam:

A nova racionalidade propõe um tremendo desafio à esquerda: não podendo contentar-se com uma crítica incisiva à "mercantilização generalizada", ela tem que inventar uma resposta política "à altura" do que o regime normativo dominante tem de inédito. Na medida em que esse último implica o definhamento irreversível da democracia liberal, a esquerda não pode contentar-se em defender a democracia liberal, como tende a fazer. Não que ela não deva mais defender as liberdades públicas, mas deve evitar fazê-lo em nome dessa democracia, por exemplo, opondo "autoritarismo neoliberal" e "democracia liberal". ${ }^{6}$

22 Essas, dentre outras indicações, permitem afirmar que, nas duas formulações, os referidos autores dedicam-se a discutir as direções e objetivos que devem referenciar as lutas anticapitalistas já no presente, fazendo com que as formas e meios de lutas experimentados sejam desde já um privilegiado espaço de elaboração de relações e de novas subjetividades regidas por lógicas distintas das disseminadas pelo regime normativo dominante.

23 Entendendo que as questões postas pelos autores trazem contribuições relevantes para a compreensão e o enfrentamento dos impasses atuais relacionados às perspectivas de futuro, são apresentados, neste artigo, aspectos das formulações acima destacadas que explicitam o pensamento dos respectivos autores sobre as lutas anticapitalistas a partir do presente, sobre as sociedades pós-capitalistas e sobre as mudanças estratégicas consideradas fundamentais para a superação histórica do capitalismo. São também consideradas as observações dos autores a respeito dos variados níveis e escalas em que se organizam tanto as ações hegemônicas como as de resistência e oposição ao regime dominante.

24 Considerando-se que o quadro de disputas político-econômicas deflagrado a partir de 2008 tem implicado alterações nas análises e nas prospecções relativas ao fim do capitalismo e à sua superação, o trabalho tem como fontes principais as obras dos autores sobre o tema a partir desse marco temporal.

\section{A trajetória dos autores}

David Harvey é um geógrafo britânico radicado desde fins da década de 1960 nos Estados Unidos da América, atuando desde o ano de 2001 como professor da City University of New York. Sua obra se destaca, especialmente, pela tentativa de compreensão da questão espacial na e a partir da obra de Karl Marx. Segundo Paul Claval, desde a década de 1970, suas pesquisas são caracterizadas tanto pela tentativa de compreensão da "dinâmica do capital [como] motor essencial da evolução do mundo contemporâneo", quanto pela "vontade de construir uma ciência útil à classe operária, aos pobres, aos excluídos, aos marginais"7. Esta marca se mostra presente na sua extensa e regular agenda de interlocuções com variados movimentos sociais e de participações em fóruns políticos e acadêmicos em variados países e continentes.

Pierre Dardot e Christian Laval têm sua atuação acadêmica vinculada à Universidade Paris-Ouest Nanterre-La Défense, o primeiro como filósofo e pesquisador, especialista 
no pensamento de Karl Marx e Georg Wilhelm Friedrich Hegel, e o segundo como professor de sociologia, especialista em liberalismo e particularmente no pensamento de Jeremy Bentham. Ambos são pesquisadores associados ao Laboratório Sophiapol, da mesma universidade. Seu trabalho conjunto é especialmente marcado pela criação, em 2004, do grupo de estudos e pesquisas Question Marx, destinado à discussão do pensamento de Marx e do marxismo, entendida como condição para a renovação do pensamento crítico. Considerados como renovadores do debate intelectual francês e internacional sobre o neoliberalismo, têm uma trajetória de regular interlocução com variados movimentos sociais, como os de cunho altermundialista, os sindicatos e outros coletivos profissionais ou de reflexão e de ação, estabelecendo com esses movimentos uma relação de discussão e análise das proposições que deles emanam ${ }^{8}$.

O vínculo dos autores com a produção do conhecimento científico e com a interlocução permanente com a prática e o pensamento dos movimentos sociais os qualifica de forma peculiar em relação ao debate sobre o caráter da dominação capitalista e das suas possibilidades de superação, destacando-se sua ênfase no estabelecimento de relações não tuteladas com os movimentos e as forças sociais e políticas.

\section{0 capitalismo hoje}

A necessidade de compreensão das especificidades atuais do capitalismo é destacada pelas duas formulações aqui apresentadas. Para ambas, as mudanças em curso do capitalismo não se constituem como mera superação de crises cíclicas, que marcam a história geral do capitalismo, bastante discutidas nas teorias dos ciclos, de Nikolaï Kondratiev, e das inovações tecnológicas, de Joseph Schumpeter. Trata-se, agora, de uma crise permanente que põe em xeque não só o modelo de produção e circulação de mercadorias vigente até a crise dos anos 1970, mas todas as formas de relacionamento na sociedade capitalista.

Para Harvey, o capitalismo contemporâneo encontra-se completamente mergulhado numa crise gerada pelo próprio capital devido a sua incapacidade de manter as relações sociais por meio das quais garante historicamente seus lucros no processo de acumulação ampliada. Observa que a crise gerada nos anos 1970 - relacionada à ampliação da concorrência comercial em face da mundialização da economia, ao esgotamento da capacidade do Estado de gerir e investir na esfera produtiva e à nova escala de uso da tecnologia na substituição do trabalho vivo - foi tratada, pelos capitalistas, como uma mera mudança estrutural. Mas os colapsos financeiros ocorridos em 2008 puseram em evidência a impropriedade das perguntas e das respostas tecidas pelo próprio capital, até aquele momento, a respeito do caráter da crise e da sua solução.

Sob o argumento de reorganizar a economia em bases sustentáveis, o capital impôs medidas que no curto, médio e longo prazos vêm ampliando a concentração de renda, restringindo as mediações políticas possíveis com a classe trabalhadora, limitando os investimentos sociais e de infraestrutura, explorando o fundo público e os recursos naturais de forma espoliativa, distorcendo os usos e sentidos de instituições que até então constituíam a base do sistema democrático, dentre outros problemas que agudizam a face social da crise, explicitando contradições que "dão a entender que não há saída sem a destruição da vida e da subsistência de milhões de pessoas no mundo todo" 9 . 
31 Entendendo que a crise em curso comporta uma multiplicidade de aspectos que não têm o mesmo peso e proeminência na sua deflagração, Harvey enfatiza que a atuação orientada para a superação crítica dessas condições econômicas, políticas e sociais requer, neste momento, que saibamos discernir, dentre a multiplicidade de contradições que se conjugam de diferenciadas formas sob o capitalismo, aquelas que são as contradições próprias do capital diretamente implicadas com a produção da crise permanente que está instalada.

Definindo o capitalismo como "qualquer formação social em que os processos de circulação e acumulação do capital são hegemônicos e dominantes no fornecimento e moldagem das bases materiais, sociais e intelectuais da vida social"10, Harvey lembra que nem tudo o que é vivido na sociedade capitalista é diretamente relacionado com o processo de acumulação de capital em si. Certamente, este usa as contradições históricas e as aprofunda a seu favor, mas isto não quer dizer que elas foram geradas univocamente pelo "motor" do próprio capitalismo, ou seja, o capital.

Por exemplo, questões de gênero e de racismo, que afetam as relações humanas desde tempos imemoriais, além das questões relacionadas às oposições entre coletividades, como o nacionalismo e as diferenças étnicas e religiosas, são certamente importantes e precisam ser tratadas política e socialmente como tal, mas não explicam o cerne da crise, que é inevitavelmente vinculado à própria dinâmica do capital no seu movimento de acumulação. A crise atual não tem sua definição e permanência na variedade de conflitos aí implicados, mas nas próprias dificuldades encontradas pelo capital em se reproduzir de forma ampliada.

Os elementos centrais da dinâmica de acumulação são os relacionados às formas de produção de valor e à sua relação com a produção de mercadorias. Nesse sentido, o principal aspecto da crise em curso é a incapacidade do capital em manter suas próprias formas históricas de acumulação ampliada, centradas em formas de exploração da força de trabalho no interior do sistema produtivo que, mesmo que intensas, ancoravam-se reiteradamente em variados modos de negociação de garantias da vida coletiva que davam à própria acumulação novos fôlegos. As formas pelas quais o próprio capital enfrenta a crise, atualmente, vêm reiteradamente rompendo os limites até então resguardados (ou restaurados) de convivência entre capital e trabalho. 0 crescimento exponencial sem limites que o capital impõe a si mesmo implica o crescimento igualmente exponencial de formas de espoliação de todos os elementos constitutivos das forças produtivas, com desdobramentos imprevisíveis para as relações do capital com o Estado, com a apropriação da natureza e com a vida humana.

Nos termos de Harvey: "o motor econômico do capitalismo está nitidamente passando por dificuldade. Oscila entre soltar faísca e parar de repente ou explodir esporadicamente sem nenhum alerta" ${ }^{11}$. As próprias ações e estratégias de recuperação da crise atual, por parte e na perspectiva do próprio capital, demonstram sua perda de controle sobre as forças produtivas e suas dificuldades para manter o "equilíbrio" por meio das formas participativas da democracia clássica. Há também evidências de perda de controle das próprias formas de geração de valor. No curso progressivo dessa crise, o capital não mantém minimamente aspectos estruturantes do seu próprio movimento de acumulação ampliada, descartando condições gerais que já foram fundamentais para sua expansão e legitimidade. Entra, assim, em uma fase profundamente espoliativa, com um grau de indeterminação tão intenso que põe sob risco os mais variados aspectos da própria sobrevivência planetária. 

raízes do sistema capitalista, ou seja, nas bases da produção do valor por meio das estruturas produtivas de mercadorias, produção esta que é ancorada na tríade histórica constituída pela produção, pela circulação e pelo consumo. Desde seu ponto de vista, o debate crítico precisa entender que a agudização da acumulação no marco atual só pode ser enfrentada por formas de compreensão e ação claramente referidas ao cerne dessa crise, cujo ponto de fragilidade fundamental são as contradições próprias do capital, ou seja, aquelas diretamente relacionadas aos aspectos centrais da produção e circulação das mercadorias - como, por exemplo, o desemprego tecnológico. Essas contradições são importantes para o próprio movimento de acumulação ampliada do capital, desde que sejam por ele relativamente manejadas, o que implica evitar sua deflagração ou manter sua progressão sob relativo controle.

limitar a uma espécie de controle em negativo dessas contradiçós, deixando que a insegurança crescente, a instabilidade a criminalização das lutas, a restriç̃̃o das práticas democráticas e a ameaça de descarte humano desagreguem e atenuem as possibilidades de reação à realização, sem mediações, de suas intencionalidades. É por meio dessa estratégia predatória que se mantém o movimento de acumulação e expansão do capital. É, portanto, exatamente sobre essa estratégia, que arrisca irresponsavelmente a vida planetária, que precisam ser focadas as ações anticapitalistas, que devem ser ações de disputa dessa lógica errática a favor do curto circuito do capital.

Para Pierre Dardot e Christian Laval, a compreensão do capitalismo implica capacidade de apreensão da heterogeneidade das formas por meio das quais, no curso da história, delineiam-se suas modalidades práticas de dominação. Nesse sentido, o neoliberalismo é entendido não como ideologia ou orientação econômica que simplesmente dá prosseguimento ao capitalismo, mas como forma contemporânea que, constituindo o capitalismo, modifica-o profundamente, revelando-se como "um sistema normativo que ampliou sua influência ao mundo inteiro, estendendo a lógica do capital a todas as relações sociais e a todas as esferas da vida" ${ }^{12}$.

39 Essa extensão da influência neoliberal a todas as esferas da vida está implicada com a sua constituição como uma racionalidade política que conta com condições específicas para sua disseminação. Mais que dirigir a produção econômica e as decisões políticas que lhes são favoráveis, o neoliberalismo pretende - e tem conseguido - a própria produção do sujeito neoliberal, universalizando, de tal forma, a concorrência como norma, que ela não apenas se torna a razão estruturante e ordenadora do mercado, do Estado e de suas ações, como, ultrapassando as próprias fronteiras do Estado, convertese em norma de conduta individual, afetando eticamente os indivíduos ${ }^{13}$. É segundo essa processualidade que a razão neoliberal se afirma como "nova razão do mundo".

Essa produção subjetiva tem consequências políticas devastadoras, porque o modelamento de modos de ser, pensar e agir socialmente aí implicados tem um peso fundamental na eliminação da estrutura da democracia liberal e na instituição de uma governamentalidade "ademocrática".

41 O neoliberalismo atua diretamente, e a partir de variados meios, sobre as condições coletivas e os próprios espaços institucionais que poderiam ser tomados como base para a sua confrontação e reversão. O sistema neoliberal se apoia em uma coalizão de poderes concretos oligárquicos ("oligarquias burocráticas e políticas, multinacionais, 
atores financeiros, e grandes organismos econômicos internacionais"14) que intervêm no funcionamento de instituições e mecanismos do próprio Estado capitalista, os quais, em tempos anteriores, foram instaurados e funcionaram como bases e meios (contraditórios, mas exatamente por isto amplamente aceitos) da democracia liberal. Essa coalizão de poderes atua direta e indiretamente na "primazia absoluta do direito privado" e no consequente "esvaziamento progressivo de todas as categorias do direito público" no sentido "de uma desativação de sua validade operatória"15.

43 Ao mesmo tempo, "as formas de gestão na empresa, o desemprego e a precariedade, a dívida e a avaliação" acionam a concorrência interindividual, minando as disposições e condições de construção do coletivo, enfraquecendo a própria capacidade de agir contra o neoliberalismo ${ }^{16}$. Nesse contexto, desativa-se o jogo democrático e a própria política como atividade ${ }^{17}$.

É a partir desse trajeto analítico que o neoliberalismo é entendido, pelos autores, como um sistema pós-democrático. Ele assinala e realiza sistematicamente a eliminação (ou a tentativa de eliminação, bem sucedida, até o presente momento) da questão democrática, tal como constituída nos marcos liberais, como referência e mediação das relações sociais e do Estado.

45 É dessa análise do capitalismo e de sua atualidade histórica como neoliberalismo que os autores derivam os elementos centrais de sua análise dos movimentos sociais contemporâneos, identificando os princípios e características que teriam potência de efetiva contraposição ao que nucleia a própria potência da racionalidade neoliberal.

\section{As lutas anticapitalistas atuais e a confrontação ao capitalismo}

Os autores considerados tomam as lutas anticapitalistas concretas e suas formas e estratégias de embate como fonte para a discussão das possibilidades e dos caminhos de enfrentamento do capitalismo, assim como de constituição de uma sociedade regida por outros princípios.

Entendendo que a história do capitalismo não é constituída por um desenvolvimento contínuo linear e unilateral, e nem pelo desdobramento evolutivo de contradições cuja dinâmica levaria invariavelmente a seu fim, Dardot e Laval argumentam que as metamorfoses do capitalismo vinculam-se a variados motivos e processos que abarcam seus próprios "descarrilamentos", as "lutas que o transformam" e as "estratégias que o renovam"18.

Se combater o capitalismo exige análises rigorosas das condições e processos relacionados a essas metamorfoses, descarrilamentos e renovações, parte fundamental desse combate depende de que tais análises considerem em profundidade também as condições, os conteúdos e as formas das lutas concretas que contrariam, de diferentes modos, a lógica capitalista.

Lembrando que o neoliberalismo implica a dissolução do modelo de democracia que por muito tempo forjou o tipo de coesão social que deu sustentação ao Estado capitalista, os autores propõem que a contraposição ao neoliberalismo não pode se limitar à defesa da democracia liberal, exigindo, ao contrário, a elaboração de princípios e práticas que afirmem modos de organização da vida coletiva confrontantes com o princípio da concorrência e com sua extensão como norma a todas as esferas da vida. 
50 Para discutir os princípios e práticas que apresentem essa potência, reportam-se aos movimentos e lutas surgidos no mundo, no início do século XXI, identificando, dentre suas características, aquelas que prefiguram novas práticas e instituições orientadas por princípios de cooperação.

51 Reportando-se a variados movimentos, mobilizações e insurreições democráticas, como os contrários às transformações neoliberais das universidades e à privatização da água, ao domínio dos oligopólios e dos Estados sobre a internet, ou ainda à "apropriação dos espaços públicos pelos poderes privados e estatais" ${ }^{19}$, observam que, dessas formas de contestação à ordem atual, emerge o princípio do comum como elemento que atravessa variados aspectos de seus modos de organização e de ação.

Dentre os aspectos indicativos da originalidade histórica dessas mobilizações, destacam a "tendência a querer unir forma e conteúdo, meios e objetivo". Uma de suas exigências práticas centrais é "não mais separar o ideal democrático que eles perseguem das formas institucionais que eles adotam", o que implica "a recusa em empregar meios tirânicos para atingir fins emancipadores". Essa tentativa de união entre forma e conteúdo, meios e objetivo, é também o que leva esses movimentos a não naturalizarem as formas políticas institucionalizadas. Problematizando a delegação a partidos e à representação parlamentar, tais movimentos buscam formas variadas de autogoverno ${ }^{20}$.

Entendem, porém, que o alcance histórico duradouro dessas mobilizações requer que suas experiências se desdobrem na invenção de novas instituições ${ }^{21}$. Recordam, neste caso, as experiências de organização em diferentes escalas que já vêm instaurando princípios, práticas e meios que podem e devem se constituir como base de instituições futuras. $O$ "novo internacionalismo prático" que "já se encontra em ação nos combates atuais" é destacado pelos autores como um exemplo evidente das condições de emergência dessa invenção, tendo em vista a originalidade, seja das coordenações de ação instauradas nos fóruns mundiais do altermundialismo, seja das formas de circulação de análises e de palavras de ordem transmitidas por sites e redes sociais ${ }^{22}$.

Harvey também se reporta a inúmeras lutas sociais, em particular, as empreendidas pelos movimentos sociais urbanos, identificando-as como fundamentais para a emergência de uma "política anticapitalista". Mostra-se cético, porém, quanto aos desdobramentos diretos desses movimentos em processos anticapitalistas de larga escala.

Referindo-se às grandes manifestações de massa, de caráter relativamente espontâneo, que, a partir dos anos 2000, tem levado grandes multidões a espaços públicos, seja pela defesa de direitos, seja por confrontações específicas ao poder político instituído ${ }^{23}$, chama atenção para suas fragilidades, em especial no que diz respeito a sua capacidade de permanência e de resistência frente às tentativas de seu controle e reabsorção pelas próprias práticas capitalistas dominantes.

Outro tipo de movimento discutido são os relacionados a tentativas de criação de formas alternativas de organização econômica, sob o controle de trabalhadores, para enfrentar as determinações capitalistas. São lembrados, neste caso, os movimentos de autogestão produtiva e de cooperativas de trabalhadores, projetos de propriedade comunitária e de sistemas econômico-mercantis locais, como os movimentos de economia solidária, em vários países da América Latina, e o Movimento Zapatista, no México. 
57 A esse respeito, Harvey entende que, apesar de seus esforços, os movimentos concretos desse tipo não se mostraram até agora viáveis como modelos para soluções anticapitalistas mais globais. Reconhece que eles conseguem lograr formas relevantes de sucesso na escala local, mas tal sucesso só permanece, nas experiências em curso, na medida em que tais movimentos se mantenham significativamente fechados em si. Considera que, a despeito desses limites, tais movimentos podem infringir danos consideráveis ao capitalismo. Mas lembra que, assim que esse dano se torna evidente, o capital reage por meio de ações vorazes que tendem a levar esses movimentos à liquidação ${ }^{24}$.

Reitera, neste caso, a centralidade que as contradições do capital devem ter na organização, expansão e agregação das lutas anticapitalistas. Identificando e analisando algumas contradições reais diretamente relacionadas ao movimento do capital, argumenta que, pensadas em conjunto, elas podem, em tempos de crise, como a deflagrada entre 2007 e 2009, criar "oportunidades para uma luta anticapitalista sistêmica" ${ }^{25}$. A melhor compreensão dessas contradições, por parte dos movimentos anticapitalistas e da esquerda, é o que possibilitaria que essas forças saibam o que esperar em linhas gerais dos seus desdobramentos, podendo tirar melhor proveito da forma como essas "contradições circulam e se aprofundam (tanto geográfica quanto setorialmente) durante a formação e a resolução da crise, em vez de serem surpreendidos e frustrados por elas" 26 .

Construída nesses termos, a ação dos movimentos sociais teria chances de transpor os limites próprios da democracia liberal (e do tipo de humanismo que lhe corresponde), circunscritos a noções e condições de exercício de direitos que não interferem na lógica da acumulação. A compreensão dessas contradições e a identificação de suas fragilidades estruturais fundamentariam práticas e lutas sociais não circunscritas aos equilíbrios já constituídos ${ }^{27}$, possibilitando avançar na construção de um humanismo revolucionário capaz de orientar estratégias de crítica, confronto e verdadeira superação da ordem capitalista e com dos princípios liberais que domesticam e ordenam os conflitos na chamada democracia liberal.

\section{Pós-capitalismo}

60 Ainda que em relação ao futuro pareça predominantemente cético, Harvey não elimina a possibilidade de transformações que, orientadas por um humanismo revolucionário, possam produzir esperanças concretas de construção de uma sociedade de novo tipo. Compreendemos que seu ceticismo expressa uma percepção lúcida do futuro, em que cenários utópicos de paz social não serão conquistados automaticamente, como se o capitalismo fosse a única razão perversa do mundo e a quebra da hegemonia do capital sobre as formações sociais abolisse por si as desigualdades. Ao contrário, as mudanças nas práticas sociais, nas referências coletivas e nos comportamentos, envolvendo novas perspectivas de lidar com a produção e a distribuição da riqueza socialmente produzida, exigirão amadurecimentos sociais e ainda muitos conflitos.

61 A expressão do ceticismo de Harvey pode ser observada na avaliação que tem do futuro próximo, em que, seguindo "a posição de Marx"28,

provavelmente o capital continuará funcionando para sempre, mas provocará uma degradação progressiva da terra e um empobrecimento em massa, aumentando radicalmente a desigualdade social e a desumanização de grande parte da humanidade, a qual se verá submetida a uma negação cada vez mais repressiva e 
autocrática de seu potencial de florescimento humano individual (em outras palavras, uma intensificação da vigilância policial totalitária promovida pelo Estado, do sistema de controle militarizado e da democracia totalitária que já vivemos hoje em larga escala).

62 A percepção de Harvey nessa passagem revela um pessimismo que põe em evidencia que as formas de organizar as diferentes estruturas produtivas e mesmo os diferentes processos e relações de produção, envolvendo o uso e manejo das tecnologias, a organização do mercado de trabalho e a distribuição do consumo, dentre outros aspectos, continuarão sendo objetos de disputas, pois as contradições e conflitos não se resolverão com o fim do capitalismo. Isso nos parece coerente e até mesmo evidente: se considerarmos que a histórica da humanidade é a história da luta de classes ${ }^{29}$, com certeza o fim do capitalismo não representará o fim da história.

Com efeito, Harvey trabalha sempre com a possibilidade de superação do capitalismo, mas, considerando o enraizamento e estruturas do sistema, indica que os "tremores", que antecederão o grande "terremoto" que poderá por fim ao capitalismo, provavelmente terão "consequências imediatas [que] não serão boas para ninguém"30.

Portanto, a perspectiva para o futuro exige ações que tenham em conta a luta de classes e estratégias claras de enfrentamento das contradições e conflitos de novo tipo que certamente surgirão. Para Harvey, "Se um movimento anticapitalista viável aparecer, será então preciso reavaliar as estratégias anticapitalistas passadas e presentes. É preciso, portanto, dar um passo atrás e refletir o que pode e deve ser feito, quem o fará e onde" ${ }^{31}$.

Os destaques que Harvey apresenta para delinear um campo estratégico de ação que possa contribuir para o fim do capitalismo e, ao mesmo tempo, para já esboçar estratégias de organização social em uma sociedade pós-capitalista, são as contradições que, em seu livro 17 contradições e o fim do capitalismo, ele define como "as contradições perigosas", que são perigosas por se relacionarem a aspectos que estão na base da crise econômica, ambiental e humanitária do capitalismo contemporâneo e que seguirão como contradições perigosas em qualquer modo de produção que possa vir a se formar. Os três aspectos destacados, neste caso, também são apresentados no livro Cidade rebeldes: do direito à cidade à revolução urbana, no qual o autor adverte que as eventuais soluções, "formas de organização e agendas políticas propostas devem oferecer resposta a três questões fundamentais" 32 .

A primeira é a superação da necessidade do capital de manter taxas de crescimento composto, pois os volumes de capitais acumulados no sistema mundo e a concentração nos sistemas financeiros tornam impraticável a obtenção de taxas de crescimento que contemplem o retorno ampliado para os capitais que buscam investimentos no mundo. Harvey estima que uma taxa de $3 \%$ ao ano seria, para o capital, uma medida suficiente para manter seu crescimento exponencial. o problema é que, se já era difícil manter as taxas de acumulação ampliada em 1970, quando era necessário encontrar oportunidades de investimentos para 6 bilhões de dólares na economia mundial, hoje há que se encontrar investimentos para 2 trilhões de dólares disponíveis a cada ano no sistema econômico. A realização da taxa de $3 \%$ ao ano sobre essa base implica, inevitavelmente, a adoção de uma lógica espoliativa de todo e qualquer recurso. Uma contraposição a esse movimento implica a busca de uma economia mundial que convirja para uma taxa de crescimento igual a zero. Ou seja, que a produção de bens 
não seja mais destinada à acumulação ampliada, como valor de troca, passando a prevalecer seu valor de uso.

67 A segunda questão se relaciona aos graves perigos da degradação ambiental e das transformações ecológicas descontroladas. É necessário transformar a concepção humana da natureza. As alterações ambientais e econômico-sociais relacionadas à produção crescente de energia natural, a intensificação do agronegócio e o consequente crescimento da absorção da água nas atividades agrícolas, o esgotamento dos recursos naturais são expressão da completa subsunção da produção energética, agrícola e extrativista ao processo de acumulação do capital. As mudanças neste campo implicariam um enfrentamento rigoroso dessa subsunção, envolvendo limitações para sua inscrição na ciranda do crescimento exponencial que, por sua vez, requerem alterações nos padrões de uso dos recursos relacionadas a alterações substantivas no estilo no estilo de vida, nas formas de urbanização e no produtivismo que encara a natureza como mercadoria, dentre outros aspectos.

68 A terceira questão está na forma como são tratados a humanidade, em geral, e os trabalhadores, em particular, em um mundo em que a exploração do trabalho e a alienação estão comprometendo cada vez mais as possibilidades de liberdade e de exercício da capacidade criadora humana. A questão é relativa a um esmagador processo de empobrecimento que não se restringe à destituição material, mas envolve uma produção subjetiva ancorada no individualismo dos sujeitos, no estranhamento social, na ampliação da concorrência entre indivíduos e na degradação das possibilidades de exercício intelectual, com graves repercussões sobre as referências e práticas solidárias. Tendo este quadro em consideração, Harvey entende que as organizações contra a pobreza precisam se comprometer com uma política contra a riqueza projetada para uma escala global, envolvendo a construção de relações sociais alternativas às que são dominantes.

Estas são, para o autor, questões que ajudam a "definir o que pode implicar o anticapitalismo" e a "oferecer razões racionais para se tornar anticapitalista" ${ }^{3}$, fornecendo bases para ações e lutas que assumam, efetivamente, um caráter de confrontação da lógica de acumulação exponencial infinita que acelera a instauração da barbárie em nosso mundo. A construção de um pós-capitalismo que não seja um desdobramento e ampliação dessa barbárie implica a construção das condições de realização dessa confrontação, sendo este um desafio particularmente central. Primeiro, porque a necessidade de decisivos enfrentamentos ao capitalismo e ao Estado ultramilitarizado tem como obstáculos a indiferença, o ceticismo e a descrença enraizados "na alienação universal" ${ }^{34}$. Segundo, porque, se "Nunca antes a escolha entre o socialismo e a barbárie se colocou de forma tão incisiva numa conjuntura histórica", paradoxalmente, "nunca antes a ampla esquerda foi tão fraca" ${ }^{35}$. Frente a este quadro, o movimento fundamental de "descobrir novas formas de fazer política anticapitalista", implica, necessariamente, superar as fragmentações existentes, ampliando o alcance e a duração das lutas "contra todas as formas de discriminação, opressão e repressão violenta do capitalismo" e articulando-as com "a luta contra o capital e suas contradições" ${ }^{36}$.

70 A sociedade contraposta ao capitalismo pensada por Pierre Dardot e Christian Laval é uma sociedade regida pelo princípio do comum. Mas os autores não apresentam um modelo ou uma caracterização sistemática de uma sociedade futura, pós-capitalista, erguida a partir desse princípio. 
71 Alertando que não acreditam em leis da história e em revelações sobre o que deverá ser, apresentam-se como "adeptos da experimentação prudente e ponderada de novas práticas, ao menos na medida em que as circunstâncias o permitirem"37.

72 Nesse sentido, apresentam proposições teóricas e práticas que "não formam um conjunto acabado e muito menos um programa"38, mas espécies de enunciados que convidam à reflexão e "que valem essencialmente como premissas de um raciocínio que apenas as lutas práticas poderão construir e desenvolver"39.

73 Porém, é possível extrair, dessas proposições teóricas e práticas, uma pré-figuração parcial, imaginativa ${ }^{40}$, de uma sociedade pós-capitalista instituída a partir do princípio do comum.

74 Essas proposições aparecem, indireta ou diretamente ao longo das duas principais obras aqui consideradas, mas são principalmente sistematizadas na parte final da segunda obra $^{41}$ e sintetizadas na forma de uma súmula das ideias centrais sobre os sentidos e as possibilidades revolucionárias do comum, em um texto anexado ao final da referida publicação, denominado de Post-scriptum sobre a revolução do século XXI.

75 Nessas proposições, o comum é definido como "o governo dos homens, das instituições e das regras que eles adotam para organizar suas relações", entendido como autogoverno fundado "no agir comum, fonte dos direitos e das obrigações" 42 , de "novas instituições, novas obras, novas relações e novas práticas" ${ }^{43}$.

$76 \mathrm{Na}$ compreensão dos autores, "uma política deliberada do comum visará criar instituições de autogoverno que possibilitem o desenvolvimento mais livre possível desse agir comum". Reconhecem, porém, que isto só pode se dar "dentro dos limites estabelecidos pelas sociedades, isto é, conforme as regras de justiça estabelecidas por elas e com as quais elas estarão de acordo" 44 .

77 Coerentemente com os desafios de contraposição à extensão do princípio de concorrência a todas as esferas da vida, realizada pelo neoliberalismo, a política do comum, relacionada à instituição de uma nova sociedade, também “diz respeito a todas as esferas sociais, e não só às atividades políticas, no sentido parlamentar e partidário do termo, nem às atividades econômicas apenas", sendo transversal às separações instituídas e orientada à efetivação de uma exigência democrática generalizada, que alcance todos os domínios de ação humana e afirme que os homens participem "das regras que os afetam, do governo das instituições nas quais atuam, vivem e trabalham ${ }^{45}$.

78 Assim, afirmam a necessidade de uma política do comum, entendendo-a como "uma política que faça do comum o princípio de transformação do social" nas mais variadas esferas e escalas da vida coletiva, afirmando, entre outros aspectos, uma nova concepção de direito, definida em franca oposição ao direito de propriedade; uma nova concepção de sujeito, contraposta à que se relaciona à disseminação do empreendedorismo; e uma nova concepção e prática de federalismo que, dando forma institucional ao auto-governo ${ }^{46} \mathrm{com}$ base na cooperação, seja claramente contraposta às práticas federativas que historicamente vêm sendo usadas, em diferentes âmbitos (comercial, institucional, político-governamental etc.) como formas políticas de organização e governo de concorrências. 


\section{Conclusões}

79 A leitura dos textos mais recentes dos autores aqui destacados possibilita perceber que as suas principais contribuições para o debate sobre as possibilidades pós-capitalistas são pelo menos de três tipos. Eles contribuem para esse debate pelas formas como apresentam os processos hegemônicos, identificando seus elementos estruturantes e seus pontos de sustentação; pela identificação que fazem dos modos de agir que podem sustentar a emergência e consolidação de relações sociais confrontantes com as relações necessárias aos processos hegemônicos, atingindo e fragilizando seus elementos estruturantes e seus pontos de sustentação; e pelas correlações que estabelecem entre essas possíveis formas de ação confrontante e as formas concretas de lutas que vêm sendo desenvolvidas.

Dentre as questões tratadas pelos autores como fundamentais para a ampliação da potência das lutas anticapitalistas, pode-se destacar, primeiramente, a necessidade de mudanças subjetivas coletivas que impliquem restrições ao capital em sua dinâmica de acumulação. Essa dinâmica de acumulação, dirigida pela busca de taxas de crescimento exponencial, faz com que o capital aja de forma devastadora contra as forças produtivas, sobretudo contra a força de trabalho. As mudanças subjetivas referidas pelos autores, neste caso, relacionam-se, especialmente, à constituição de referências éticas capazes de fomentar práticas sociais que colidam com a lógica instrumental à dinâmica capitalista, definida, dentre outros aspectos, pela concorrência e pela naturalização do consumo de bens, a rigor, desnecessários.

81 Ambas as formulações destacam, nesse sentido, a necessidade de se construir um novo marco da relação do homem com a natureza, um marco cultural que, para além da defesa geral do meio ambiente, implique alteração das disposições sociais em relação às práticas lesivas das condições ambientais e das condições de acesso das coletividades aos meios necessários a sua existência. A esse respeito, os autores chamam atenção para a necessidade de enfrentar tanto as formas espoliativas com que o capital industrial tem se relacionado com a natureza, como as práticas cotidianas da sociedade, que mantém um consumo excessivo de produtos cuja produção e descarte implicam exploração destrutiva dos recursos naturais e degradação ambiental.

Outra preocupação comum às formulações se refere à necessidade de desenvolvimento de meios de combate à riqueza, de forma a se restringir a formação de grandes fortunas ${ }^{47}$, principalmente as construídas por meio da espoliação aberta das pessoas e da natureza, muitas vezes de modos ilícitos mascarados por formas variadas de tendenciosa legalidade. Não se trata de uma empreitada moral contra a riqueza individual. Trata-se do estabelecimento de marcos jurídico-políticos e mesmo institucionais que inviabilizem a produção de acumulação da riqueza constituída a partir de domínios institucionais e outras formas de corrupção e improbidade lesivos a interesses sociais.

83 Um outro ponto comum importante de se destacar diz respeito ao entendimento de que as lutas e experiências dos movimentos sociais e dos trabalhadores têm que se disseminar em escala global e têm que encontrar meios de agregação para alcançarem efeitos efetivamente anticapitalistas. Ainda que inúmeras experiências autogestionárias concorram para a formação coletiva de novas formas de pensar e agir restritivas aos princípios do capitalismo e possam mesmo ajudar a corroer suas bases, seu fechamento em limites específicos (territoriais, setoriais, institucionais...) contém seus impactos e 
facilita as contra-investidas desarticuladoras e mesmo exterminadoras do capital. A disseminação dessas lutas e experiências em escala global, no entanto, não implica sua homogeneização e a abolição da ação em variadas escalas. Dardot e Laval chegam a falar da possibilidade de criação de federações mundiais que não se constituam como instâncias de governo dos outros âmbitos de organização, mas como instâncias de correlação entre os variados níveis de organização prática, de luta e de ação.

Entendemos que essas formulações, apesar de seus inevitáveis limites, são uma tentativa vigorosa de interpretação da conjuntura econômica e política contemporânea com vistas à identificação das condições e das possibilidades de seu enfrentamento. Não se tratando de propostas voltadas à apresentação de receituários de transformação revolucionária, tão pouco podem ser reduzidas a propostas meramente reformistas. A nosso ver, não eliminam a perspectiva de transformação revolucionária dirigida pelo antagonismo entre o capital e o trabalho, mas tentam pensar a processualidade dessa transformação, recusando-se a cristalizar as forças sociais e políticas nas suas configurações passadas, e, ao contrário, partindo do máximo de atenção às formas contemporâneas reais de constituição dessas forças, considerando sua composição, seus dinamismos, suas práticas e comportamentos.

Assim, de nosso ponto de vista, ao se situarem no marco delicado e, ao mesmo tempo necessário, de pensar a ação política sem desqualificar as utopias, mas também sem projetar sobre ela prescrições arbitrárias, ambas as formulações representam esforços reais de pensar as possibilidades de práticas de mudanças assentadas em condições e sujeitos concretos, capazes de, ao longo desse processo, atuarem sobre sua própria formação.

\section{BIBLIOGRAFIA}

ALTVATER, Elmar. O fim do capitalismo como o conhecemos: Uma crítica radical ao capitalismo. Rio de Janeiro: Civilização Brasileira, 2010.

ANDRADE, Daniel Pereira e OTA, Nilton Ken. Uma alternativa ao neoliberalismo. Entrevista com Pierre Dardot e Christian Laval Tradução do francês de Naira Pinheiro dos Santos. Tempo Social, vol.27, nº 1, São Paulo Jan./June 2015.

BORÓN, Atílio (Org.). Nova hegemonia mundial: alternativas de mudança e movimentos sociais. Buenos Aires: Editora Clacso, 2004.

CHESNAIS, François et al. Uma nova fase do capitalismo? São Paulo: Xamã, 2003.

CLAVAL, Paul, Marxismo e geografia econômica na obra de David Harvey, Espaço e

Economia [Online], 3 | 2013, URL: http://journals.openedition.org/espacoeconomia/570 ; DOI :

1.4000/espacoeconomia. 570

DARDOT, Pierre e LAVAL, Christian. A nova razão do mundo: ensaios sobre a sociedade neoliberal. Tradução: Mariana Echalar. São Paulo: Boitempo, 2016. 
DARDOT, Pierre e LAVAL, Christian. Comum: ensaio sobre a revolução do século XXI. Tradução Mariana Echalar. $1^{\mathrm{a}}$ Edição. São Paulo: Boitempo, 2017.

GRAMSCI, Antonio. Cadernos do cárcere (V. 3). Maquiavel. Notas sobre o Estado e a política. Rio de Janeiro: Civilização Brasileira, 2000.

HARVEY, David. Cidades rebeldes: do direito à cidade à revolução urbana. São Paulo: Martins Fontes, 2014.

HARVEY, David. 17 contradições e o fim do capitalismo. São Paulo: Boitempo, 2016.

MARX, Karl e ENGELS, Friedrich. O manifesto comunista. Rio de Janeiro, Editora Paz e Terra, Coleção Leitura, 14 $4^{\mathrm{a}}$ edição, 2004.

MÉSZÁROS, István. O século XXI: socialismo ou barbárie? Trad. Paulo Cezar Castanheira. São Paulo: Boitempo Editorial, 2003.

SARAMAGO, José. Ensaio sobre a cegueira. São Paulo, Companhia das Letras, 1995.

SMITH, Neil (et al.). Después del neoliberalismo: ciudades y caos sistémico. Barcelona: MACBA; $\mathrm{UAB}, 2009$.

WALLERSTEIN, Imanuel. Após o Liberalismo: em busca da reconstrução do mundo. Petrópolis, Rio de Janeiro: Vozes, 2002.

WALLERSTEIN, Imanuel. La crisis estructural del Capitalismo. Bogotá, D.C.-Colômbia: Ediciones Desde Abajo, 2007.

WOOD, Ellen Meiksins. Democracia contra o Capitalismo: a renovação do materialismo histórico. São Paulo: Boitempo, [1995] 2006.

\section{NOTAS}

1. Como em Neil Smith et alii (2009) e em Elmar Altvater (2010).

2. Como em Imanuel Wallerstein (2002 e 2007), István Mészáros (2003), Ellen Wood (2003), François Chesnais et alii (2003) e Atílio Borón (2004), dentre outros.

3. Especialmente nas obras em que discute o direito à cidade e lutas urbanas anticapitalistas (Cidades rebeldes: do direito à cidade à revolução urbana, 2014, publicado originalmente na Inglaterra e nos Estados Unidos da América em 2012) e questões relativas às possibilidades de fim do capitalismo frente às suas contradições (17 contradições e o fim do capitalismo, 2016, publicado originalmente na Inglaterra em 2014).

4. Especialmente nas obras em que sistematizam sua crítica ao neoliberalismo como nova racionalidade (A nova razão do mundo: ensaios sobre a sociedade neoliberal, 2016, publicado originalmente na França em 2009) e em que apresentam sua proposição a respeito do princípio do comum como princípio de agregação instaurador de outra racionalidade (Comum: ensaio sobre a revolução do século XXI, 2017, publicado originalmente na França em 2014).

5. Harvey, 2016, p. 271.

6. Dardot e Laval, 2016, p. 389, grifos dos autores.

7. Claval, 2013, p. 15.

8. Sobre a forma particular de relação dos autores com os movimentos, reportamo-nos à síntese por eles próprios efetuada, em entrevista concedida a Daniel Pereira Andrade e Newton Ken Ota (2015).

9. Harvey, 2016, p. 21.

10. Harvey, 2016, p. 19. 
11. Harvey, 2016, p.12.

12. Dardot e Laval, 2016, p. 7

13. Dardot e Laval, 2016, p. 378-379

14. Dardot e Laval, 2016 p. 8.

15. Dardot e Laval, 2016, p. 378.

16. Dardot e Laval, 2016, p. 9.

17. Dardot e Laval, 2016, p. 10.

18. Dardot e Laval, 2016, p. 11.

19. Dardot e Laval, 2017, p. 481.

20. Dardot e Laval, 2017, p. 481.

21. Dardot e Laval, 2017, p. 481-482.

22. Dardot e Laval, 2017, p. 487.

23. Seriam exemplo desse tipo volátil de movimento de massa as manifestações contrárias à Guerra do Iraque, em 2003, as revoltas nos subúrbios franceses, em 2005, as ações do Movimento Occupy Wall Street, em 2011 e as manifestações por direitos urbanos no Brasil, em 2013.

24. Harvey, 2014, p. 224.

25. Harvey, 2014, p. 25.

26. Harvey, 2014, p.25.

27. Essa ideia de Harvey remete claramente às formulações de Gramsci a respeito da "grande política", relacionada a questões de destruição, conservação ou transformação "de determinadas estruturas orgânicas econômico-sociais", e da "pequena política", relacionada às questões "que surgem no interior de um equilíbrio já constituído e que não tentam superar aquele equilíbrio para criar novas relações" (GRAMSCI, 2000, p. 21-22).

28. Harvey, 2014:205.

29. Marx e Engels, 2004, p. 9: “A história de todas as sociedades que já existiram é a história de luta de classes".

30. Harvey, 2016, p. 270.

31. Harvey, 2016.

32. Harvey, 2014, p. 228.

33. Harvey, 2016, p. 277.

34. Harvey, 2016, p. 280.

35. Harvey, 2016, p. 280.

36. Harvey, 2016, p. 286-287.

37. Dardot e Laval, 2017, p. 482.

38. Dardot e Laval, 2017, p. 482.

39. Dardot e Laval, 2017, p. 483.

40. Nas palavras dos autores: "Examinar o comum como princípio efetivo de transformação de nossas instituições pressupõe um exercício de imaginação política, ou mesmo de projeção histórica, com todos os limites que o gênero comporta e que devemos assumir" (Dardot e Laval, 2017, p. 482).

41. Dardot e Laval, 2017.

42. Dardot e Laval, 2017, p. 485.

43. Dardot e Laval, 2017, p. 486.

44. Dardot e Laval, 2017, p. 486.

45. Dardot e Laval, 2017, p. 486.

46. Dardot e Laval, 2017, p. 486.

47. Um exemplo das formas de riqueza altamente concentradoras, que deveriam ser confrontadas, pode ser encontrado nos dados de concentração da riqueza no Brasil, onde apenas 6 pessoas têm "juntos, a mesma riqueza que os 100 milhões mais pobres do país, ou seja, a metade 
da população brasileira (207,7 milhões)", conforme reportagem do jornal El País, Brasil, de 25/09/2017.

\section{RESUMOS}

O artigo apresenta formulações de David Harvey, de Pierre Dardot e Christian Laval a respeito das mudanças recentes do capitalismo, das realidades objetiva e subjetiva produzidas por essas mudanças, das tentativas reais de confrontação de sua lógica e das lições que se pode extrair dessas experiências para pensar sua superação. Considerando que a forma trágica de disseminação mundial da enfermidade nomeada Covid-19 resulta das escolhas políticas e econômicas acionadas pelo capital a favor da acumulação exponencial ilimitada, busca destacar formulações contemporâneas que contribuem de forma contundente para a compreensão dos processos que levam aos eventos destrutivos e para o fortalecimento de lhçioformas de pensar e agir capazes de disputar um futuro distinto para a humanidade.

El artículo presenta formulaciones de David Harvey, Pierre Dardot y Christian Laval con respecto a los cambios recientes en el capitalismo, las realidades objetivas y subjetivas producidas por estos cambios, los intentos reales de confrontar su lógica y las lecciones que pueden extraerse de estas experiencias para piensa en superarlo. Considerando que la forma trágica de diseminación mundial de la enfermedad llamada Covid-19 es el resultado de las elecciones políticas y económicas desencadenadas por el capital en favor de la acumulación exponencial ilimitada, busca resaltar las formulaciones contemporáneas que contribuyen fuertemente a la comprensión de los procesos que conducen a eventos destructivos y para el fortalecimiento de formas de pensar y actuar capaces de disputar un futuro diferente para la humanidad.

Cet article analyse les formulations de David Harvey, Pierre Dardot et Christian Laval à propos des aspects suivants: les changements capitalistes les plus récentes et les réalités objective et subjective qui en déroulent ; les efforts réels capables de confronter la logique capitaliste actuel ; et les leçons qu'on peut extraire de tout ce contexte afin de réfléchir sur le dépassement du capitalisme. En considérant que la façon tragique de la dissémination mondiale de la Covid-19 est le résultat des choix politico-économiques à la faveur de l'accumulation exponentielle illimitée, on souligne la force de la pensée et de l'action contemporaines aptes à concevoir un avenir assez distincte pour l'humanité.

The article presents formulations by David Harvey and Pierre Dardot and Christian Laval regarding the recent changes in capitalism, the objective and subjective realities produced by these changes, the real attempts to confront its logic and the lessons that can be drawn from these experiences for think your overcoming. Considering that the tragic form of worldwide dissemination of the disease named Covid-19 results from the political and economic choices triggered by capital in favor of unlimited exponential accumulation seeks to highlight contemporary formulations that strongly contribute to the understanding of the processes that lead to destructive events and to the strengthening of ways of thinking and acting capable of disputing a different future for humanity. 
ÍNDICE

Palavras-chave: crise do capitalismo, pandemia, movimentos anticapitalistas, transformação social, acumulação capitalista.

Mots-clés: Crise capitaliste, pandémie, mouvements anticapitalistes, changement social, accumulation capitaliste.

Palabras claves: crisis del capitalismo, pandemia, movimientos anticapitalistas, transformación social, acumulación capitalista.

Keywords: capitalism crisis; pandemic; anticapital movements, social change; capitalist accumulation.

\section{AUTORES}

EVELINE ALGEBAILE

Universidade do Estado do Rio de Janeiro ealgebaile@gmail.com

\section{FLORIANO JOSÉ GODINHO DE OLIVEIRA}

Universidade do Estado do Rio de Janeiro

fgodinho@uerj.br 